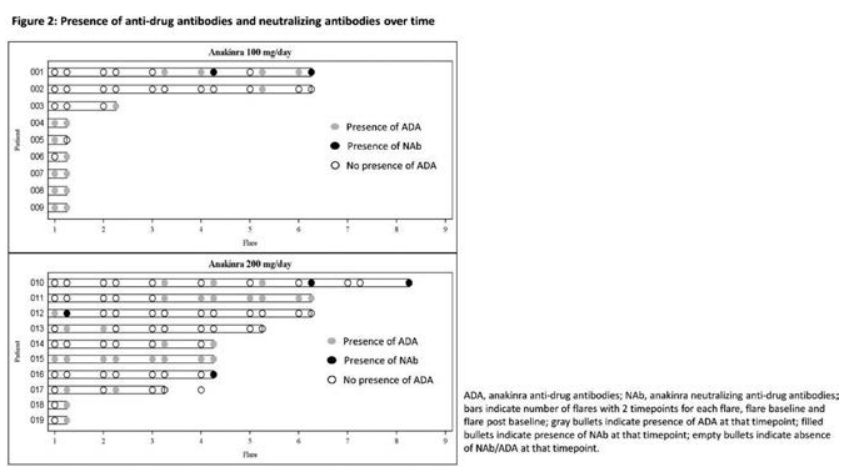

Disclosure of Interests: : Kenneth Saag Grant/research support from: Horizon, Sobi, Shanton, Grant/research support from: Horizon Pharma, Sobi, Shanton, Consultant of: Horizon and Sobi, Consultant of: Horizon Pharma, Amgen, Radius, LG-Pharma, Takeda, Sobi, Atom, Arthrosi, Puja Khanna Grant/research support from: Dyve, Selecta, Sobi, Consultant of: Sobi, Horizon, Robert Keenan Consultant of: Sobi, Selecta, Horizon, Sven Ohlman Shareholder of: Sobi, Employee of: Former employee of Sobi, Erik Sparve Shareholder of: Sobi, Employee of: Sobi, Daniel Lindqvist Employee of: Sobi, Ann-Charlotte Åkerblad Shareholder of: Sobi, Employee of: Sobi, Margareta Wikén Shareholder of: Sobi, Employee of: Former employee of Sobi, Alexander So Consultant of: Sobi, Grünenthal, Michael H. Pillinger Grant/research support from: Horizon, Hikma, Consultant of: Sobi, Horizon, Robert Terkeltaub Consultant of: Sobi, Selecta, Horizon, Astra-Zeneca DOI: 10.1136/annrheumdis-2020-eular.3813

\section{THU0440 LOW DOSE COLCHICINE COMBINED WITH SPORADIC INTRAMUSCULAR INJECTIONS OF BETAMETHASONE - EFFICIENT AND SUSTAINED TREATMENT OF ACUTE GOUTY ARTHRITIS}

A. Sargsyan ${ }^{1}$, V. Vardanyann ${ }^{2,3}$, K. Ginosyan ${ }^{3}$, S. Vardanyan ${ }^{2}$, V. Mukuchyan ${ }^{4}$. ${ }^{1}$ Yerevan State Medical University, Yerevan, Armenia; " "Mikayelyan"Institute of Surgery, Yerevan, Armenia; ${ }^{3}$ Yerevan State Medical University, Yerevan, Armenia; 4"Erebouni" Medical Center, Yerevan, Armenia

Background: Gouty arthritis is a common, potentially disabling and increasingly prevalent disease [1]. The main goals of treatment are to treat acute arthritis, decrease uric acid (UA) levels and prevent occurrence of further attacks. According to 2016 updated EULAR evidence-based recommendations for the management of gout, the most common and efficient options include prescription of colchicine (up to $6 \mathrm{mg}$ during the first day) and intra-articular injections of glucocorticoids (GC) [2]. First option often causes diarrhea, the latter is extremely traumatic and painful in this group of patients.

Objectives: The aim of this study was to determine the efficacy of sustainability of anti-inflammatory effect of combination of low dose colchicine with sporadic intramuscular injections of betamethasone in the treatment of acute gouty arthritis.

Methods: 41 treatment naïve patients with acute gouty arthritis (27 male /65,9\%/, 14 female $/ 34,1 \% /$, mean age $55,9 \pm 13,7$ years, mean disease duration $5,9 \pm$ 4,4 years) were recruited in the study. On the first visit all the patients were prescribed $1.5 \mathrm{mg}$ of colchicine per day and 2 intramuscular injections of betamethasone preparation $(7 \mathrm{mg}-1 \mathrm{ml})$ with an interval of 4 days. On the second visit $\left(30^{\text {th }}\right.$ day) daily dose of colchicine was decreased to $1.0 \mathrm{mg}$, urate-lowering therapy (ULT) was begun. 21 patients $(51,2 \%)$ received febuxostat $80 \mathrm{mg} /$ day, 20 patients $(48,8 \%)$ - allopurinol $100-150 \mathrm{mg} /$ day.

Routine investigation included accurate collection of disease history, objective examination with determining the disease activity (Gout Activity Score /GAS/) and visual analogue scale (VAS patient), CBC, CRP, measurement of serum UA and creatinine level, urinalysis and other examinations [4]. GAS, VAS, CRP and uric acid were measured 3 times: at baseline, on $30^{\text {th }}$ and $60^{\text {th }}$ day of follow-up period.

Results: Investigation had shown the following results at baseline: sUA $-9,2 \pm$ $1,5 \mathrm{mg} / \mathrm{dll}, \mathrm{CRP}_{1}-24,3 \pm 21,5 \mathrm{mg} / \mathrm{L}, \mathrm{VAS}_{1}-8,3 \pm 1,3 \mathrm{~cm}, \mathrm{GAS}_{1} 6,3 \pm 0,7$. All enrolled patients completed 60 days of treatment. Preparations were well tolerated, no serious adverse events occurred: mild dyspepsia was observed in $4(9,8 \%)$ patients, mild hypertension - in $7(17,1 \%), 10(24,4 \%)$ patients had transient diarrhea. Only in 14 out of 41 patients $(34,1 \%)$ there was a necessity to add NSAIDs to the main scheme of treatment.
On the second visit $\left(30^{\text {th }}\right.$ day) all investigated measures with exception for UA $\left(\mathrm{sUA}_{2}-8,8 \pm 1,9 \mathrm{mg} / \mathrm{dl}, \mathrm{p}>0.05\right)$ had shown significantly lower results: $\mathrm{CRP}_{2}$ $4,9 \pm 3,5 \mathrm{mg} / \mathrm{dl}, \mathrm{VAS}_{2}-4,2 \pm 1,2 \mathrm{~cm}, \mathrm{GAS}_{2}-4,9 \pm 0,7$ ( $\left.p<0.001\right)$.

On the third visit $\left(60^{\text {th }}\right.$ day) the following results were obtained: $\mathrm{SUA}_{3}-4,7 \pm$ $1,3 \mathrm{mg} / \mathrm{dl}, \mathrm{CRP}_{3}-3,5 \pm 2,0 \mathrm{mg} / \mathrm{L}, \mathrm{VAS}_{3}-3,3 \pm 2,1 \mathrm{~cm}, \mathrm{GAS}_{3}-3,7 \pm 0,9$. All the measures were significantly lower than at baseline $(p<0,001)$.

During all the follow-up period recurrent attacks of arthritis were observed in 6 patients (14,6\%), particularly, only 2 patients experienced arthritis after the prescription of ULT.

Conclusion: Low dose colchicine in combination with sporadic (1-2) intramuscular injections of betamethasone can present as an efficient, non-traumatic, safe and cost-effective option for the treatment of acute gouty arthritis. Moreover according to results of our study, anti-inflammatory effect was stable even after the prescription of ULT.

\section{References:}

[1] Kuo C-F, Grainge MJ, Zhang W, et al. Global epidemiology of gout: prevalence, incidence and risk factors. Nat Rev Rheumatol 2015;11:649-62. doi: 10.1038/nrrheum.2015.91

[2] Richette P, et al. 2016 updated EULAR evidence-based recommendations for the management of gout Ann Rheum Dis 2017;76:29-42. doi:10.1136/ annrheumdis-2016-209707

[3] Scirè, Carlo $A$ et al. "Development and First Validation of a Disease Activity Score for Gout." Arthritis care \& research vol. 68,10 (2016): 1530-7. doi:10.1002/acr.22844

Disclosure of Interests: : None declared

DOI: 10.1136/annrheumdis-2020-eular.3762

\section{THU0441 DIAGNOSTIC ACCURACY OF THE NIJMENGEN SCORE FOR GOUTY ARTHRITIS IN PATIENTS HOSPITALIZED FOR ACUTE MONOARTHRITIS}

M. Schmitt ${ }^{1}$, A. Ramon ${ }^{2}$, P. Ornetti ${ }^{2}$, J. F. Maillefert ${ }^{2} .{ }^{1}$ Dijon University Hospital, Dijon, France; ${ }^{2}$ Dijon University Hospital, Dijon, France

Background: The gold-standard for diagnosis of gout is the identification of monosodium urate (MSU) crystal in joint fluid. However, the sensitivity, specificity, and reproducibility of such analysis are not excellent, and joint aspiration is sometimes difficult, or impossible. The Nijmengen score is an easy-to-use rule without joint fluid analysis with excellent validity, in primary as well as in secondary care $(1,2)$. However, it's validity as not been evaluated in the particular situation of patients whose acute arthritis necessitates hospitalization

Objectives: The objective of the present study was to assess diagnosis performances of the score in patients hospitalized for acute monoarthritis.

Methods: Inclusion: all patients hospitalized for acute monoarthritis in the rheumatology department of the Dijon University Hospital between 2016 and 2019 Assessment: 1- clinical examination by an experimented rheumatologist; 2- joint aspiration and synovial fluid analysis following aspiration; 3- ultrasound (US) examination of the knees, first metatarso-phalangeal joints, and arthritic joint by a trained rheumatologist; 4- dual-energy computed tomography (DECT) of the arthritic joint; 5- Nijmengen score (cutoff scores of $\geq 8$ needed for diagnosis of gout, and $\leq 4$ to rule out gout) and ACR/EULAR 2015 classification criteria (3) (cut-off score of $\geq 8$ needed for diagnosis of gout). Analysis: positive and negative predictive values, and ROC curve analysis of the Nijmengen score, using as gold-standard on one hand the results of the MSU crystal research, on the other hand those of the ACR/EULAR criteria.

Results: A total of 39 patients were included (mean age $=69.8 \pm 15$ years, $74.4 \%$ males, mean BMI $=27.5 \pm 4.6 \mathrm{Kg} / \mathrm{m} 2$, mean serum uric acid $=354.6 \pm$ $117.5 \mu \mathrm{mol} / \mathrm{l})$. The affected joints were the knee $(n=31)$, ankle $(n=3)$, hip $(n=$ $2)$, wrist $(n=2)$, shoulder $(n=1)$. Joint fluid analysis revealed MSU crystal in 11 patients. The ACR/EULAR was $\geq 8$ in 15 patients. The Nijmengen score was $\geq$ 8 in 11 patients, including 5 with MSU crystal on joint fluid analysis and 9 with an ACR/EULAR score $\geq 8$. The Nijmengen score was $\leq 4$ in 15 patients, including 14 with no MSU crystal on joint fluid analysis and 14 with an ACR/EULAR score $<8$. The positive predictive values of a Nijmengen score $\geq 8$ were $45 \%$ (joint fluid analysis as gold standard) and $81.8 \%$ (ACR/EULAR). The negative predictive values of a Nijmengen score $\leq 4$ were $93.3 \%$ (joint fluid analysis and $\mathrm{ACR} / \mathrm{EULAR}$ as gold standard). On ROC curve analyses, the areas under the curve were $0.763(95 \% \mathrm{Cl}=0.612-0.914)$ using joint fluid analysis as gold standard (figure 1) and $0.908(95 \% \mathrm{Cl}=0.814-1.0)$ using the ACR/EULAR score as gold standard (figure 2). 